\title{
The Changing Arctic Cryosphere and Likely Consequences: An Overview
}

\author{
M. S. Olsen, T. V. Callaghan, J. D. Reist, L. O. Reiersen, D. Dahl-Jensen, \\ M. A. Granskog, B. Goodison, G. K. Hovelsrud, M. Johansson, \\ R. Kallenborn, J. Key, A. Klepikov, W. Meier, J. E. Overland, \\ T. D. Prowse, M. Sharp, W. F. Vincent, J. Walsh
}

\begin{abstract}
The Arctic cryosphere is a critically important component of the earth system, affecting the energy balance, atmospheric and ocean circulation, freshwater storage, sea level, the storage, and release of large quantities of greenhouse gases, economy, infrastructure, health, and indigenous and non-indigenous livelihoods, culture and identity. Currently, components of the Arctic cryosphere are subjected to dramatic change due to global warming. The need to document, understand, project, and respond to changes in the cryosphere and their consequences stimulated a comprehensive international assessment called "SWIPA": Snow, Water, Ice, Permafrost in the Arctic. Some of the extensive key SWIPA chapters have been summarized and made more widely available to a global audience with multi-disciplinary interests in this Special Report of Ambio. In this article, an overview is provided of this Special Report in the context of the more detailed and wider scope of the SWIPA Report. Accelerated changes in major components of the Arctic cryosphere are documented. Evidence of feedback mechanisms between the cryosphere and other parts of the climate system are identified as contributing factors to enhanced Arctic warming while the growing importance of Arctic land-based ice as a contributor to global sealevel rise is quantified. Cryospheric changes will result in multifaceted and cascading effects for people within and beyond the Arctic presenting both challenges and opportunities.
\end{abstract}

Keywords Climate change - Snow - Permafrost . Arctic · Feedbacks · Ecology - Sea level .

Greenland Ice Sheet - Mountain glaciers · Ice caps .

Sea ice $\cdot$ Lake ice $\cdot$ River ice $\cdot$ Society $\cdot$ Culture .

Peoples

\section{INTRODUCTION}

The Arctic cryosphere is a critically important component of the earth system. It affects the energy balance of the earth that results in a net cooling of the earth's surface; its dynamic processes affect air and ocean circulation at a global scale; it stores freshwater from seasonal to millennial time scales and thereby regulates the availability of freshwater during the growing season and affects sea level and thus the extent and shape of the earth's land masses, which determine the surface available for human habitation. Furthermore, the Arctic's cryosphere is an important regulator of the storage and release of large quantities of greenhouse gases, such as methane and carbon dioxide. Currently, major components of the Arctic cryosphere are subjected to dramatic change due to climate warming. The need to document, understand, project, and respond to changes in the cryosphere and their consequences has greatly stimulated recent research and assessment activities. In 2005, the Arctic Council (www.arctic-council.org/) published the comprehensive report "Arctic Climate Impact Assessment" (ACIA 2005), which drew global scientific and political attention to the effects of climate change in the Arctic. Observations of further cryospheric change in the first decade of the 21st century spurred the Arctic Council to launch a follow up assessment to the ACIA: the "Snow, Water, Ice, and Permafrost in the Arctic" (SWIPA; www.amap.no/swipa) project, the results of which were published in 2011 (AMAP 2011).

The SWIPA report (AMAP 2011) is comprehensive, containing 542 pages and 12 chapters (available from http://www.amap.no/swipa/). Within a Special Report of Ambio, "A Journal of the Human Environment", some of the extensive SWIPA chapters have been summarized to 
make this information more widely available to a global audience with multi-disciplinary interests. This has been achieved by identifying and focusing on key issues from many of the SWIPA chapters by the original lead authors (Callaghan et al. 2011a [this issue]). In this article, we provide an overview of the Special Report of Ambio in a context of the more detailed and broadly based SWIPA Report (AMAP 2011).

\section{RESULTS}

\section{Changes in Climate}

During the past decade, the Arctic has experienced the highest temperatures of the instrumental record while recent paleo-reconstructions show that current Arctic summer temperatures are higher than at any time in the past 2000 years (Walsh et al. 2011a, b [this issue]). The Arctic Ocean has experienced enhanced oceanic heat inflows from both the North Atlantic and the North Pacific, and its heat storage has increased in newly sea-ice free areas of the ocean. The increase in ocean heat storage has had an increased influence on autumn atmospheric temperature and wind fields and is consistent with increased cloudiness. A detectable feedback between sea-ice loss and Arctic air temperature has emerged since the publication of the ACIA report in 2005. Storm events and extreme high temperatures also show signs of increases. Walsh et al. (2011a, b [this issue]) show large year-to-year variability in precipitation over the land areas north of $55^{\circ} \mathrm{N}$, including some especially wet years during the past decade, superimposed on an increase of about $5 \%$ since 1950

The above noted changes are consistent with the trends projected by global climate models (GCMs) as described in the modeling chapter of the SWIPA report (Overland et al. 2011) and the trends described should continue and should dominate Arctic environmental change by the later decades of the 21 st century. Although details depend on location, time of year, model, and assumed future increases in greenhouse gas emissions, the consensus suggests a general increase in Arctic-wide autumn and winter surface air temperatures of $3-6^{\circ} \mathrm{C}$ by 2080 , a nearly sea ice-free September by 2050 , and a general increase in precipitation over future decades.

Owing to the random influence of natural variability, the future that we will experience will differ somewhat from the smooth average of the range of possible future trajectories derived from GCMs. For example, the observed sea-ice loss in summer 2007 was greater than most trajectories projected by the GCMs (Meier et al. 2011).

\section{Changes in Snow Cover}

The widespread warming and increasing winter precipitation in the Arctic during the past 40-50 years have resulted in different regional snow-cover responses (Callaghan et al. $2011 \mathrm{~b}, \mathrm{c}$ [this issue]). The largest decreases in snow-water equivalent (SWE) and snow-cover duration (SCD) occurred over maritime regions and the most prolonged decreases in snow cover and snow depth have occurred in the North American sector. Although snow depths are increasing in many regions of Eurasia, warming and more frequent winter thaws are contributing to changes in snowpack structure. GCMs project increases in maximum SWE of up to $15 \%$ over much of the Arctic by 2050 but SCD is projected to decrease by about 10-20\% (Callaghan et al. 2011c [this issue]).

These projected changes will have far-reaching consequences for the climate system, biogeochemical cycling, hydrology, ecology, and human well-being (Callaghan et al. 2011b, d [this issue]; Hovelsrud et al. 2011a, b [this issue]; Prowse et al. 2011a, b [this issue], c [this issue]; Vincent et al. 2011a, b [this issue]). Snow cover plays a major role in the Arctic system through its influence on the surface energy balance (e.g., reflectivity), water balance (e.g., water storage and release), thermal regimes (e.g., insulation), vegetation, and trace gas fluxes (Callaghan et al. 2011b, d [this issue]). The livelihoods and well-being of Arctic residents and many services for the wider population depend on snow conditions so changes have important and far-reaching consequences (Hovelsrud et al. 2011a, b [this issue]): winter thaw events and rain-on-snow conditions have negatively affected commercial forestry and reindeer herding while the physical and emotional health of Arctic residents could be compromised. However, there are also likely to be benefits of changing Arctic snow conditions, such as more stable snowmelt runoff that is projected to benefit the hydropower industry.

\section{Permafrost}

Permafrost presence and its dynamics are major drivers of hydrological and geomorphological processes in the Arctic that affect ecology, biogeochemical cycling, water resources, and infrastructure maintenance and development. The SWIPA report (AMAP 2011) documents increases in permafrost temperatures that have occured throughout the Arctic despite high regional variation in the rates and magnitudes of climate warming (Callaghan et al. 2011e). Increasing permafrost temperatures are generally consistent with changes in the thickness of the active layer (the surface layer above permafrost that thaws in summer) that has already increased progressively over much of Eurasia and central Alaska where there has also been a 
recent loss of permafrost from several lower latitude sites formerly characterized by discontinuous permafrost. Projections indicate that by 2100 there will be widespread permafrost degradation throughout much of the Arctic. The multiple consequences of these changes for landforms (e.g., ground slumping and slope instability), ecosystems (e.g., drying of wetland habitats in some areas and pond formation in others), biogeochemical cycling (e.g., increases in methane emissions from new wetlands and release of significant amounts of carbon stored in, or capped by permafrost), and infrastructure (particularly along coastlines with ice-rich unconsolidated materials) can be profound (Callaghan et al. 2011e). Some of the possible important risks of thawing permafrost, particularly the release of methane from continental shelves, are highly uncertain.

\section{Lake and River Ice}

Lake and river ice are interwoven into the arctic terrestrial landscape through major water flow and storage networks. As such, they significantly affect numerous bio-physical and socio-economic systems (Prowse et al. 2011a, b [this issue]). The effects of freshwater ice on climate mostly occur at the local/regional scale, with the degree of influence dependent on the magnitude, timing, location, and duration of ice cover, and the size of the water body. Freshwater-ice formation, growth, decay, and break-up are influenced by climatic variables that control surface heat fluxes, but these differ markedly between lakes and rivers (Prowse et al. 2011a, c [this issue]). Despite the importance of freshwater ice, there has been a recent reduction in observational recordings (Key 2011).

Palaeolimnological and instrumental records indicate that some Arctic lakes may have crossed an important ecological threshold as a result of recent warming and long-term trends that exhibit increasingly later freeze-ups and earlier break-ups (Prowse et al. 2011a, d [this issue]). These trends are projected to continue in the future and will be accompanied by decreasing ice thickness, and changes in ice cover composition, particularly white-ice. Such changes will also produce a variety of effects on hydrologic, ecological, and socio-economic systems (Prowse et al. 2011a, b [this issue]; Hovelsrud et al. 2011a, b [this issue]).

\section{Mountain Glaciers and Ice Caps}

Observations assessed in the SWIPA Report show general declines in mass and volume of mountain glaciers and ice caps in the Arctic over the past century with substantial increases in rates of decline since 1995 (Sharp et al. 2011). The total mass losses may have exceeded $150 \mathrm{Gt}$ per year over the past decade (comparable to the mass loss from the Greenland Ice Sheet: see below), making Arctic glaciers a significant contributor to global sea-level rise. Half of the loss is from glaciers in the Canadian Arctic and southern Alaska. Continuing losses due to warming are projected, with the greatest losses projected for the Canadian Arctic and Alaska, followed by Svalbard and the Russian Arctic. The consequences of declines in mountain glacier ice cap mass and volume include exposure of new land and altered drainage and water output patterns, initial increases in runoff followed by eventual declines as glacier area decreases, and water outbursts of several types, e.g., glacier lake dams fail. Increased iceberg formation and continued break-up of ice shelves (until they disappear completely from the Arctic) are also expected, and these may create hazards in the marine environment.

\section{The Greenland Ice Sheet}

The Greenland Ice Sheet is the second largest body of stored freshwater on Earth. Until 1990, the total amount of ice added to and lost each year from the Greenland Ice Sheet was roughly in balance (Dahl-Jensen et al. 2011a). However, mass losses by both meltwater and ice discharge have increased since 1990 and the inputs and losses are no longer in balance. The estimated recent rate of net mass loss from the Greenland Ice Sheet is four times that of earlier estimates (i.e., $205 \pm 50 \mathrm{Gt}$ per year for 2005-2006 compared to $50 \pm 50 \mathrm{Gt}$ per year for 1995-2000). Increased ice discharge is primarily due to accelerated flow in many of the fast-flowing glaciers that terminate in ocean water in the fjords apparently triggered by contact with warmer ocean water. The major impact of the loss of ice is an increasing contribution to sea-level rise while other consequences relate to coastal and marine habitats (see below). Impacts on the near-surface stratification of the subpolar North Atlantic Ocean are also possible.

\section{Sea Ice}

Arctic sea ice extent has declined over all seasons since 1979, although less in other seasons than summer. The average extent of the summer (September) minimum sea ice cover has declined by $25-30 \%$ since estimates based on satellite information began in 1979. The decline in Arctic summer sea ice extent has accelerated over the past 10 years and the last 5 years (2007-2011) have had the five lowest extents in the record. Sea ice has also thinned and older, thicker ice types have been lost and not been replenished, and the majority of the ice in the Arctic Ocean is now composed of young first-year sea ice which is more susceptible to summer melt (Meier et al. 2011). The retreat is faster than previously predicted by IPCC models and 
summer ice-free conditions are likely over most of the Arctic basin by mid-century or earlier, with increasing variability in the ice cover in the intervening years. The decline in Arctic sea ice reduces albedo and results in more heat absorption by open water that in turn would enhance Arctic warming; effects on other aspects of regional and global climate are also expected (see above). Changing sea ice and snow-cover patterns will shift the balance between primary production by ice algae and phytoplankton, and there will be further uncertain consequences throughout the rest of the Arctic food web. Some ice-associated ecosystems are at risk of complete loss while others will change significantly.

\section{Sea Level}

Sea-level change is one of the more serious consequences of climate change because vast numbers of people live on or use resources on lands that are likely to be inundated. While climate change during the last century has affected sea level primarily through thermal expansion of oceanic waters, reductions in the amount of freshwater currently stored as ice on land (glaciers and ice sheets) now add significantly to sea-level rise through melt and ice discharge (Dahl-Jensen et al. 2011b). Present (2003-2008) mass losses from Arctic glaciers and the Greenland Ice Sheet contribute a total increase of $1.3 \mathrm{~mm}$ per year to the rise in global mean sea level, which is an increase since 1995. Current projections of total sea-level rise by 2100 resulting from all sources, including the Antarctic Ice Sheet and non-Arctic glaciers range from 0.79 to $2.01 \mathrm{~m}$. However, the confidence in the projections is low and a range of $0.9-1.6 \mathrm{~m}$ is considered more plausible by the authors of the SWIPA assessment (Dahl-Jensen et al. 2011a, b). Nevertheless, significant effects of rising sea level will become increasingly evident by mid-century although regional variation will be high. Effects from sea-level rise include significant inundation of low-lying areas adjacent to coasts and possibly complete submergence of some small islands. Other more imminent effects include coastal flooding, erosion, infrastructure damage, environmental impacts on ecosystems, and saltwater intrusions into groundwater.

\section{Feedbacks}

Changes in Arctic climate are a result of complex interactions between the cryosphere, atmosphere, ocean, and biosphere. More feedbacks from the cryosphere to the climate system are positive (resulting in warming) than are negative (Callaghan et al. 2011f, $g$ [this issue]). Feedbacks operate at different spatial scales: many, such as albedo decreases, will have significant local/regional effects whereas others, such as possible increases in release of subsea methane $\left(\mathrm{CH}_{4}\right)$, could have large global effects, although uncertainty is high. Already, feedbacks are implicated in some recent climatic changes. For example, the extent to which the date of spring melt has become earlier is greater than the extent to which the date of snowon has become delayed, and this is consistent with a greater early-season albedo feedback effect. Also, air warming in autumn is consistent with a feedback from reduced minimum sea ice cover. With continued climate warming it is highly likely that the Arctic's changing cryosphere will play an increasingly important climatic role. These could occur at large geographical scales through teleconnections between the Arctic and other regions and effects on atmospheric and oceanic circulation. However, the net effect of all the feedbacks is difficult to assess and even more difficult to project with current GCMs.

\section{Consequences for Ecology}

The substantial, but geographically variable changes in snow, water, ice, and permafrost in the Arctic are allowing some habitats and their associated ecosystems to expand, while others are undergoing rapid contraction (Vincent et al. $2011 \mathrm{a}, \mathrm{b}$ [this issue]). The warming of the Arctic cryosphere is limiting the habitat range for cold-adapted biota, while less specialized taxa including invasive species from the south are likely to become increasingly common in the future. Extreme climate events such as thawing in midwinter are likely to become more frequent and may accelerate shifts in community structure and processes. Many Arctic ecosystems are interdependent, and changes in the cryosphere are altering the physical, biogeochemical, and biological linkages within and between Arctic ecosystems, as well as causing positive feedback effects on atmospheric warming, for example through reduced albedo and increased emissions of greenhouse gases. All of these climate-related effects are compounded by rapid socio-economic development in the North, creating additional challenges for ecosystem management and for sustaining the traditional lifestyles of northern communities that depend on Arctic ecosystem provisioning services (such as provision of food). Provisioning services are further threatened by changes in the cryosphere that could cause a redistribution and remobilisation of anthropogenic contaminants in the Arctic (Kallenborn and Macdonald 2011) with harmful effects on wildlife. Furthermore, the important historical regulatory ecosystem services, for example feedbacks to climate, could be negated by a changing cryosphere.

\section{Consequences for People}

Changes in the Arctic cryosphere will affect economies, infrastructure, health, and indigenous and non-indigenous 
livelihoods, culture and identity (Hovelsrud et al. 2011a, b [this issue]). Arctic residents are resilient and highly adaptive, but the rate and magnitude of change challenges their current adaptive capacity. Cryospheric changes create both challenges and opportunities with local, regional, and international dimensions. Some changes, such as the loss of summer sea ice, will provide better access to the Arctic and its resources, thereby increasing human activities such as resource extraction, shipping, and tourism. However, cryospheric changes provide some challenges for international governance, human rights, safety and search and rescue efforts, and risks of environmental degradation from accidents and spills. Human society is also affected by indirect effects of a changing cryosphere, including industrial developments, globalization, and societal changes, which contribute to shaping vulnerability and adaptation options. Combined with non-cryospheric drivers of change, this will result in multifaceted and cascading effects within and beyond the Arctic.

\section{Synthesis}

From the SWIPA synthesis of the multiple cryospheric changes in the Arctic and their consequences, four especially important issues emerge: the nature and magnitude of the changes, their timing relative to the seasonal/annual cycle, the spatial and temporal scales on which they occur, and their consequences for physical and biotic systems (Reist et al. 2011). The SWIPA synthesis chapter evaluates the combined impact of these issues on the Arctic environment and its inhabitants. It concludes that the scope and nature of cryospheric changes in the Arctic, in combination with widespread climate variability, over large spatial and temporal scales, and with human adaptive capacity, will ultimately determine whether particular changes in the cryosphere are viewed as opportunities or challenges (Reist et al. 2011). The overwhelming consequence is a highly variable and uncertain future for the Arctic. Developing strategies and approaches for adaptation that take account of such uncertainty as a basic consideration is the major challenge to effective solutions. Planning for surprises or unanticipated events is likely to be increasingly important. Filling knowledge gaps by developing a more robust observing system and improving climate and cryosphere models is critical to effective planning.

\section{CONCLUSIONS}

The SWIPA assessment (AMAP 2011) documents an accelerated change in major components of the Arctic cryosphere such as sea ice, mountain glaciers and ice caps, and the Greenland Ice Sheet. The SWIPA Assessment and the current volume (Callaghan et al. 2011a [this issue]) detail and summarize indications that feedback mechanisms between the cryosphere and other parts of the climate system are already contributing to enhanced Arctic warming. The growing importance of Arctic land-based ice as a contributor to global sea-level rise is obvious. Furthermore, climate change in the Arctic is causing a change in the distribution of water in its solid and liquid states and in the timing of phase shifts that have profound effects on the physical, chemical, and biological conditions in both the Arctic and lower latitudes. The SWIPA assessment and extracts from it in this Special Report show that predictions made in the ACIA (2005) and IPCC AR4 (Solomon et al. 2007) assessments underestimate effects of climate change on the Arctic cryosphere which, in turn, underestimate cascading effects on eco- and human systems. Geographical variability in rates of change in some parts of the Arctic cryosphere is not well understood, even though satellite measurements and other long-range surveillance systems have improved observational capacity. Improved surfacebased observations and better parameterizations of Arctic cryospheric processes in GCMs are needed to improve the understanding and projections of cryospheric change. The net effect of all the feedbacks is unclear, so additional observational and modeling studies are essential.

The speed, extent, and severity of local, regional, and global effects of a changing Arctic cryosphere call for urgent and improved understanding of their combined impacts.

Acknowledgments We thank all the participants in the SWIPA process, and particularly the numerous authors of the AMAP SWIPA report and this Ambio Special Report for contributing to the completion of a comprehensive assessment of the changing Arctic cryosphere, its climatic drivers and multiple consequences. Numerous national funding agencies supported the SWIPA process and we are grateful for this support. We are grateful for financial contributions to the SWIPA production from Canada, Denmark, Norway, and Nordic Council of Ministers. We are particularly grateful to the Swedish Environmental Protection Agency (grant number 08/210) and the Swedish Research Council FORMAS (grant number 204-2009-45) for the grants to TVC and MJ for the publication of this special issue, to Environment Canada for a further grant to TDP to complete the financing of the publication, and finally to Professor F. Wrona for facilitating this.

\section{REFERENCES}

ACIA. 2005. Arctic Climate Impact Assessment. Cambridge: Cambridge University Press.

AMAP. 2011. Snow, Water, Ice and Permafrost in the Arctic (SWIPA) 2011. Oslo: Arctic Monitoring and Assessment Programme (AMAP).

Callaghan, T.V., M. Johansson, O. Anisimov, H.H. Christiansen, A. Instanes, V. Romanovsky, and S. Smith, 2011e. Chapter 5: Changing permafrost and its impacts. In Snow, Water, Ice and Permafrost in the Arctic (SWIPA). Oslo: Arctic Monitoring and Assessment Programme (AMAP). 
Callaghan, T.V., M. Johansson, R.D. Brown, P. Ya Groisman, N. Labba, and V. Radionov. 2011b. Chapter 4: Changing snow cover and its impacts. In Snow, Water, Ice and Permafrost in the Arctic (SWIPA). Oslo: Arctic Monitoring and Assessment Programme (AMAP).

Callaghan, T.V., M. Johansson, R.D. Brown, P. Ya Groisman, N. Labba, V. Radionov, et al. 2011c. The changing face of Arctic snow cover: A synthesis of observed and projected changes. In Arctic cryosphere-Changes and impacts, ed. T.V. Callaghan, M. Johansson, and T.D. Prowse. Ambio 40(S1). doi: 10.1007/s13280-011-0212-y.

Callaghan, T.V., M. Johansson, R.D. Brown, P. Ya Groisman, N. Labba, V. Radionov, et al. 2011d. Multiple effects of changes in Arctic snow cover. In Arctic cryosphere-Changes and impacts, ed. T.V. Callaghan, M. Johansson, and T.D. Prowse. Ambio 40(S1). doi:10.1007/s13280-011-0213-x.

Callaghan, T.V., M. Johansson, J. Key, T. Prowse, M. Ananicheva, and A. Klepikov. 2011f. Chapter 11.1: Synthesis of feedbacks and interactions: From the cryosphere to the climate systemeffects over various spatial and temporal scales. In Snow, Water, Ice and Permafrost in the Arctic (SWIPA). Oslo: Arctic Monitoring and Assessment Programme (AMAP).

Callaghan, T.V., M. Johansson, J. Key, T.D. Prowse, M. Ananicheva, and A. Klepikov. 2011g. Feedbacks and interactions: From the Arctic cryosphere to the climate system. In Arctic cryosphereChanges and impacts, ed. T.V. Callaghan, M. Johansson, and T.D. Prowse. Ambio 40(S1). doi:10.1007/s13280-011-0215-8.

Callaghan, T.V., M. Johansson, T.D. Prowse, M.S. Olsen, and L.-O. Reiersen. 2011a. Arctic cryosphere-Changes and impacts, ed. T.V. Callaghan, M. Johansson, and T.D. Prowse. Ambio 40(S1). doi:10.1007/s13280-011-0210-0.

Dahl-Jensen, D., J.J. Bamber, C.E. Boggild, E. Buch, J.H. Christensen, K. Dethloff, M. Fahnestock, and S. Marshall. 2011a. Chapter 8: The Greenland Ice Sheet in a changing climate. In Snow, Water, Ice and Permafrost in the Arctic (SWIPA). Oslo: Arctic Monitoring and Assessment Programme (AMAP).

Dahl-Jensen, D., K. Steffen, M. Sharp, A. Arendt, and R. Hock. 2011b. Chapter 11.2: Cross-cutting scientific issues-sea-level change. In Snow, Water, Ice and Permafrost in the Arctic (SWIPA). Oslo: Arctic Monitoring and Assessment Programme (AMAP).

Hovelsrud, G.K., B. Poppel, B. van Oort, J. Reist, D. Armitage, H. Dannevig, H. Huntington, A.L. Lovecraft, et al. 2011a. Chapter 10: Arctic societies, cultures, and peoples in a changing cryosphere. In Snow, Water, Ice and Permafrost in the Arctic (SWIPA). Oslo: Arctic Monitoring and Assessment Programme (AMAP)

Hovelsrud, G.K., B. Poppel, B. van Oort, J.D. Reist, J.L. White, H. Dannevig, S. Rybråten, D. Armitage, et al. 2011b. Arctic societies, cultures, and peoples in a changing cryosphere. In Arctic cryosphere-Changes and impacts, ed. T.V. Callaghan, M. Johansson, and T.D. Prowse. Ambio 40(S1). doi:10.1007/ s13280-011-0219-4

Kallenborn, R., and R. Macdonald. 2011. Chapter 11.3: Contaminant pathways and change in the Cryosphere. In Snow, Water, Ice and Permafrost in the Arctic (SWIPA). Oslo: Arctic Monitoring and Assessment Programme (AMAP).

Key, J. 2011. Chapter 11.5: Observational needs and knowledge gaps for the Cryosphere. In Snow, Water, Ice and Permafrost in the Arctic (SWIPA). Oslo: Arctic Monitoring and Assessment Programme (AMAP).

Meier, W.N., S. Gerland, M.A. Granskog, J.R. Key, C. Haas, G.K. Hovelsrud, K. Kovacs, A. Makshtas, C. Michel, D. Perovich, J.D. Reist, and B.E.H. van Oort. 2011. Chapter 9: Sea ice. In
Snow, Water, Ice and Permafrost in the Arctic (SWIPA). Oslo: Arctic Monitoring and Assessment Programme (AMAP).

Overland, J.E., M. Wang, J.E. Walsh, J.H. Christensen, V.M. Kattsov, and W.L. Chapman. 2011. Chapter 3: Climate model projections for the Arctic. In Snow, Water, Ice and Permafrost in the Arctic (SWIPA). Oslo: Arctic Monitoring and Assessment Programme (AMAP).

Prowse, T.D., K. Alfredsen, S. Beltaos, B. Bonsal, W.B. Bowden, C. Duguay, A. Korhola, J. McNamara, et al. 2011b. Effects of changes in arctic lake and river ice. In Arctic cryosphereChanges and impacts, ed. T.V. Callaghan, M. Johansson, and T.D. Prowse. Ambio 40(S1). doi:10.1007/s13280-011-0217-6.

Prowse, T.D., K. Alfredsen, S. Beltaos, B.R. Bonsal, C. Duguay, A. Korhola, J. McNamara, R. Pienitz, et al. 2011d. Past and future changes in Arctic lake and river ice. In Arctic cryosphereChanges and impacts, ed. T.V. Callaghan, M. Johansson, and T.D. Prowse. Ambio 40(S1). doi:10.1007/s13280-011-0216-7.

Prowse, T.D., K. Alfredsen, S. Beltaos, B. Bonsal, C. Duguay, A. Korhola, J. McNamara, W.F. Vincent, V. Vuglinsky, and G. Weyhenmeyer. 2011a. Chapter 6: Changing lake and river ice regimes: Trends, effects and implications. In Snow, Water, Ice and Permafrost in the Arctic (SWIPA). Oslo: Arctic Monitoring and Assessment Programme (AMAP).

Prowse, T.D., K. Alfredsen, S. Beltaos, B.R. Bonsal, C. Duguay, A. Korhola, J. McNamara, W.F. Vincent, et al. 2011c. Arctic freshwater ice and its climatic role. In Arctic cryosphereChanges and impacts, ed. T.V. Callaghan, M. Johansson, and T.D. Prowse. Ambio 40(S1). doi:10.1007/s13280-011-0214-9.

Reist, J., T. Callaghan, D. Dahl-Jensen, G. Hovelsrud, M. Johansson, R. Kallenborn, J. Key, W. Meier, et al. 2011. Chapter 12: SWIPA synthesis: Implications of findings. In Snow, Water, Ice and Permafrost in the Arctic (SWIPA). Oslo: Arctic Monitoring and Assessment Programme (AMAP).

Sharp, M., M. Ananicheva, A. Arendt, J.-O. Hagen, R. Hock, E. Joseberger, R.D. Moore, W.T. Pfeffer, and G.J. Wolken. 2011. Chapter 7: Mountain glaciers and ice caps. In Snow, Water, Ice and Permafrost in the Arctic (SWIPA). Oslo: Arctic Monitoring and Assessment Programme (AMAP).

Solomon, S., D. Qin, M. Manning, Z. Chen, M. Marquis, K.B. Averyt, M. Tignor, and H.L. Miller (ed.). 2007. Climate change 2007: The physical science basis. Contribution of Working Group I to the fourth assessment report of the intergovernmental panel on climate change. Cambridge: Cambridge University Press.

Vincent, W.F., T.V. Callaghan, D. Dahl-Jensen, M. Johansson, K.M. Kovacs, C. Michel, T. Prowse, J.D. Reist, and M. Sharp. 2011a. Chapter 11.4: Effects of climate change on snow, water, ice, and permafrost in Arctic ecosystems-synthesis. In Snow, Water, Ice and Permafrost in the Arctic (SWIPA). Oslo: Arctic Monitoring and Assessment Programme (AMAP).

Vincent, W.F., T.V. Callaghan, D. Dahl-Jensen, M. Johansson, K.M. Kovacs, C. Michel, T.D. Prowse, J.D. Reist, and M. Sharp. 2011b. Ecological implications of changes in the Arctic cryosphere. In Arctic cryosphere-Changes and impacts, ed. T.V. Callaghan, M. Johansson, and T.D. Prowse. Ambio 40(S1). doi:10.1007/s13280-011-0218-5.

Walsh, J.E., J.E. Overland, P.Y. Groisman, and B. Rudolf. 2011a. Chapter 2: Arctic climate: Recent variations. In Snow, Water, Ice and Permafrost in the Arctic (SWIPA). Oslo: Arctic Monitoring and Assessment Programme (AMAP).

Walsh, J.E., J.E. Overland, P.Y. Groisman, and B. Rudolf. 2011b. Ongoing climate change in the Arctic. In Arctic cryosphere-Changes and impacts, ed. T.V. Callaghan, M. Johansson, and T.D. Prowse. Ambio 40(S1). doi:10.1007/ s13280-011-0211-z. 


\section{AUTHOR BIOGRAPHIES}

M. S. Olsen ( $\square$ ) is Programme Coordinator of the Danish Arctic Climate Support Fund (Danish Ministry of Climate and Energy) which supports climate change effect monitoring programmes primarily in Greenland. Since 2009, Mr. Olsen has served as vice-chair of the Arctic Monitoring and Assessment Programme Working Group and he has been chairing the SWIPA Integration Team.

Address: Danish Energy Agency, Amaliegade 44, 1256 Copenhagen, Denmark.

e-mail: mso@ens.dk

T. V. Callaghan is a Distinguished Research Professor at the Royal Swedish Academy of Sciences and Professor of Arctic Ecology at Universities of Sheffield, UK and Lund, Sweden. He specializes in arctic ecology, and climate and UV-B radiation impacts on arctic ecosystems.

Address: Royal Swedish Academy of Sciences, 10405 Stockholm, Sweden.

e-mail: terry_callaghan@btinternet.com

J. D. Reist is a research scientist at Fisheries and Oceans Canada and works on northern fish ecology.

Address: Fisheries and Oceans Canada, 501 University Crescent, Winnipeg, MB R3T 2N6, Canada.

e-mail: Jim.Reist@dfo-mpo.gc.ca

L. O. Reiersen is the Executive Secretary for Arctic Monitoring and Assessment Programme (AMAP). He has for the last 20 years been planning and implementing significant Arctic monitoring and assessment programmes covering trends and effects of pollutants and climate change on Arctic ecosystems and humans.

Address: AMAP, P.O. Box. 8100, 0032 Oslo, Norway.

e-mail: lars-otto.reiersen@amap.no

D. Dahl-Jensen is a professor at the University of Copenhagen, working on ice core records of climate, and the history and evolution of the Greenland Ice Sheet.

Address: Niels Bohr Institutet, University of Copenhagen, 2100 Copenhagen, Denmark.

e-mail: ddj@gfy.ku.dk

M. A. Granskog is a research scientist at the Norwegian Polar Institute, working on sea ice and ocean geophysics, especially radiative transfer, and biogeochemistry, especially dissolved organic matter, in the Arctic, Antarctic and sub-arctic sea ice zones.

Address: Norwegian Polar Institute, Fram Centre, 9296 Troms $\varnothing$, Norway.

e-mail: mats.granskog@npolar.no

B. Goodison retired from Environment Canada, serves as a scientific officer with the Observing and Information Systems Department of the World Meteorological Organization. He specializes in satellite and in situ cryospheric observation, particularly for snow and solid precipitation. He currently is involved in the development of WMO's Global Cryosphere Watch (GCW), and provides scientific support to WMO's Expert Panel on Polar Observations, Research and Services. He was a member of the SWIPA Integration Team.

Address: World Meteorological Organization, 7 bis, Avenue de la Paix, Case Postale 2300, 1211 Geneva, Switzerland.

e-mail: barrygo@rogers.com

G. K. Hovelsrud is Research Director at Nordland Research Institute, and Senior Researcher at CICERO (Center for International Climate and Environmental Research-Oslo). Her research interests include the interlinked consequences of climatic and societal change on social-ecological systems in the Arctic, studies of the determinants of adaptive capacity in local communities, how to integrate local/traditional knowledge in climate change research, and developments of methods and theories of adaptation, vulnerability and adaptive capacity across societal scales.

Address: Nordland Research Institute, P.O. Box 1490, 8049 Bodø, Norway.

e-mail: grete.hovelsrud@nforsk.no

M. Johansson is a researcher at the Department of Earth and Ecosystem Sciences, Lund University and at the Royal Swedish Academy of Sciences, Stockholm, Sweden. She specializes in permafrost dynamics in relation to climate change and its impact on ecosystems. Address: Division of Physical Geography and Ecosystem Analyses, Department of Earth and Ecosystem Sciences, Lund University, Sölvegatan 12, 22362 Lund, Sweden.

e-mail: margareta.johansson@nateko.lu.se

R. Kallenborn is a professor for organic analytical chemistry at the Norwegian University of Life Sciences (UMB), Department of Chemistry, Biotechnology and Food Sciences (IKBM). In addition he holds an adjunct professor position in Arctic Environmental Technology at the University Centre in Svalbard (UNIS). He is working with fate and distribution of persistent organic pollutants in Arctic environments.

Address: Department of Chemistry, Biotechnology and Food Science (IKBM), Norwegian University of Life Sciences (UMB), Christian Magnus Falsen vei 1, Postbox 5003, 1432 Ås, Norway.

e-mail: roland.kallenborn@umb.no

J. Key is a research scientist with the U.S. National Oceanic and Atmospheric Administration's Satellite and Information Service, and is Chief of the Advanced Satellite Products Branch. He specializes in satellite remote sensing of snow, ice, and clouds in the polar regions. Address: NOAA/NESDIS, 1225 West Dayton Street, Madison, WI 53706, USA.

e-mail: Jeff.Key@noaa.gov

A. Klepikov is a physical oceanographer who works as a senior scientist at the Arctic and Antarctic Research Institute in St. Petersburg, Russia. He is currently the head of Department for the Antarctic Oceanography and Climate Studies. His research interests include physical oceanography and modeling of the Arctic and Southern Oceans, polar climate dynamics.

Address: Arctic and Antarctic Research Institute, 38 Bering Street, St. Petersburg, Russia 199397.

e-mail:klep@aari.ru

W. Meier is a research scientist at the National Snow and Ice Data Center, part of the University of Colorado, Boulder. His research interests include remote sensing of sea ice, changes in Arctic sea ice, and impacts of sea ice change on climate.

Address: NSIDC, University of Colorado, 449 UCB, Boulder, CO 80309, USA.

e-mail:walt@nsidc.org

J. E. Overland is the Leader of the Coastal and Arctic Research Division, Pacific Marine Environmental Laboratory/NOAA, Seattle, Washington. His research interests include climate change, oceanography, fisheries, and changes in the Arctic environment.

Address: Pacific Marine Environmental Laboratory, NOAA, Seattle, WA, USA.

e-mail: James.E.Overland@noaa.gov 
T. D. Prowse is a senior Research Scientist with Environment Canada and a Professor in the Department of Geography at the University of Victoria. His research focuses on the effects of climate variability and change on cold-regions hydrology, hydro-climatology, and hydroecology.

Address: Environment Canada, Victoria, BC, Canada.

Address: Department of Geography, University of Victoria, Victoria, BC V8P 5C2, Canada.

e-mail: terry.prowse@ec.gc.ca

M. Sharp is chair of Earth and Atmospheric Sciences, where he is professor of glaciology working on polar ice caps and glaciers.

Address: Earth and Atmospheric Sciences, University of Alberta, Edmonton, AB T6G 2E3, Canada.

e-mail: martin.sharp@ualberta.ca

W. F. Vincent is a Professor of Biology and Canada Research Chair at Laval University, Canada, where he is also director of the Centre for Northern Studies (CEN), and member of the Takuvik Joint
International Laboratory, Université Laval (Canada)-CNRS (France). He works on the effects of environmental change on polar aquatic ecosystems.

Address: Département de Biologie \& Centre d'Études Nordiques (CEN), Laval University, Quebec, QC G1V 0A6, Canada.

e-mail: warwick.vincent@bio.ulaval.ca

J. Walsh is a Research Professor at the International Arctic Research Center, University of Alaska, Fairbanks. His research interests include climate of the polar regions, Arctic climate change, severe weather, and the relationships between changes in climate and weather.

Address: International Arctic Research Center, University of Alaska, Fairbanks, AK, USA.

e-mail: jwalsh@iarc.uaf.edu 